THE focus of research into the process of technological innovations seems to have shifted recently to the developing countries. From the problems of 'high' technology and science-based industries, one now hears increasingly about transferring technology to the countries of the Third World; and it is not advanced technology but intermediate, or other appropriate, technology. This development in the language of technology transfer records the simple fact that innovation is a complex social (some would say cultural) process and that the experience of the western nations with technological developments will not transplant easily to other countries trying to make the transition to industrialisation.

The experience of western nations over the last two hundred years forms the historical backdrop to the manifold problems of making and implementing decisions intended to bring about modernisation. But modernisation, the author makes clear, involves the marriage of technology and civic life. By this he means that every developing society must be viewed as a complex of already existing and functioning social and economic processes and that no decision to introduce new technology can hope to succeed without an operational understanding of this fact. As if to guide the reader in the implications of these facts, the author painstakingly documents the industrial history of the western world

\section{Industrial revolutions}

\section{Gibbons}

Technology and Civic Life: Making and Implementing Development Decisions. By J. D. Mongomery. Pp. 239. (MIT: London and Cambridge, 1974.) $\$ 12.50$.

and points out the relevance of certain developments in the contemporary context of developing countries.

A recurring theme in the book is the changing relationships among three modes of development politicsnational planning, local options and individual choice-as forces that can direct the use of technology for advancing the quality of life in the undeveloped countries. This theme also provides the introduction to the theoretical structure of the work-a structure, it seems, that is deeply rooted in a behaviouralistic theory of politics. It is important to remember, cautions the author, that technological change implies changes in behaviour and that these cannot be brought about edict or fiat but must begin with a thorough grasp of the attitudinal status quo and build from that basis. But the modernisation of behaviour also cannot ignore the politics and structure of the community at the local level because individuals form an integral part of this structure and constitute its 'politics'. By the same token, modernisation cannot be achieved in any significant way by the transformation of the community at the local level alone. Because technological development requires the reorientation of all communities more or less simultaneously, unless it is directed at the national level modernisation will be a fragmented affair. Thus, the characterisation of the developmental problems is, in terms of these levels, intimately linked together. Accordingly, there are also three 'analytical orders' or levels of decision to be considered in applying technology to social purposes. The first order decisions are those which define and develop programmes for the purpose of benefiting identified elements of the society. The second are those that identify the administrative organisation or combinations of institutions that are to be assigned the role of moderniser and change agent. The third prescribes the incentive system by which administrators are to elicit modernising responses from citizens participating in the programme.

Because of its tight organisation and conceptual sophistication the book makes interesting and stimulating reading. Further, because even in advanced societies there are sectors which are becoming modernised or in need of becoming modernised, there is much in the way of insight and common sense for those in charge of regional development policies.
SPEAKING as one with a personal interest in the engineering applications of holography, I found reading this book to be a refreshing experience. In addition to contributing personally, the editor has gathered contributions from 14 other internationally recognised experts in fields of optical measurement or display. Although holography features prominently the book is by no means confined to that topic nor is it just about nondestructive testing. The title is a bit artificial and seems almost to have been chosen as an excuse to bring this work together. In spite of that, the aspects of nondestructive testing do form a thread of continuity through a work on optical measuring techniques which are biased heavily to those which use lasers and to a lesser extent to those using coherent radiation in the form of microwaves or ultrasonics.

Any would-be user of techniques of

\section{Optical measuring techniques \\ John N. Butters}

Holographic Nondestructive Testing. Edited by R. K. Erf. Pp. xvii +442 . (Academic Press: New York and London, July 1974.) $\$ 28.00 ; £ 14.00$.

coherent radiation for measurement or testing would do well to read this book. It contains descriptions of practical test layouts and a wealth of experimental 'tips' which help to maximise the usefulness of experiments from a data retrieval point of view. Typical examples are given but some readers will be disappointed to find that these are based in the main on laboratory experiments. Contributions are sectionalised by the author and fall into two categories: substantive material which forms the core of the book; and reports on significant developments. Sections in the first category contain mathematical backgrounds to the topics covered but there are some abrupt changes in style and technique. Presentation ranges from the quotation of relevant formula to fairly complex derivations extending to two or three pages. Readers wishing to gain benefit from the theoretical aspects would need a grounding in advanced mathematics.

All in all this is an excellent book for the serious user; it is well referenced and obviously emerges from a group well informed and well practised in their technology. Cited work is mainly of American origin so it may be appropriate to note that the techniques described are available in the UK at centres such as the National Physical Laboratory and the Mechanical Engineering laser facility at Loughborough University, to mention but two. 